\section{Case Reports in Ophthalmology}

Case Rep Ophthalmol 2017;8:35-39

DOI: $10.1159 / 000453332$

Publisned oninne: January 20, 2017
(C) 2017 The Author(s)

Published by S. Karger AG, Basel

www.karger.com/cop

This article is licensed under the Creative Commons Attribution-NonCommercial 4.0 International License (CC BY-NC) (http://www.karger.com/Services/OpenAccessLicense). Usage and distribution for commercial purposes requires written permission.

\title{
27-Gauge Vitrectomy for Symptomatic Vitreous Floaters with Topical Anesthesia
}

\author{
Zhong Lin $^{\mathrm{a}}$ Nived Moonasar ${ }^{\mathrm{b}}$ Rong Han $\mathrm{Wu}^{\mathrm{a}}$ \\ Robin R. Seemongal-Dass ${ }^{b}$ \\ ${ }^{a}$ The Eye Hospital, School of Ophthalmology and Optometry, Wenzhou Medical \\ University, Wenzhou, China; ${ }^{b}$ Ophthalmology Department, University of the West Indies, \\ St. Augustine, Trinidad and Tobago
}

\section{Keywords}

27-gauge cannula - Pars plana vitrectomy - Symptomatic vitreous floaters - Topical anesthesia

\begin{abstract}
Purpose: Traditionally acceptable methods of anesthesia for vitrectomy surgery are quite varied. However, each of these methods has its own potential for complications that can range from minor to severe. The surgery procedure of vitrectomy for symptomatic vitreous floaters is much simpler, mainly reflecting in the nonuse of sclera indentation, photocoagulation, and the apparently short surgery duration. The use of 27-gauge cannulae makes the puncture of the sclera minimally invasive. Hence, retrobulbar anesthesia, due to its rare but severe complications, seemed excessive for this kind of surgery. Method: Three cases of 27gauge, sutureless pars plana vitrectomy for symptomatic vitreous floaters with topical anesthesia are reported. Results: The vitrectomy surgeries were successfully performed with topical anesthesia (proparacaine, $0.5 \%$ ) without operative or postoperative complications. Furthermore, none of the patients experienced apparent pain during or after the surgery. Con-
\end{abstract}




\section{Case Reports in Ophthalmology}

Case Rep Ophthalmol 2017;8:35-39

DOI: $10.1159 / 000453332$

(C) 2017 The Author(s). Published by S. Karger AG, Basel www.karger.com/cop

Lin et al.: 27-Gauge Vitrectomy for Symptomatic Vitreous Floaters with Topical Anesthesia

clusion: Topical anesthesia can be considered for 27-guage vitrectomy in patients with symptomatic vitreous floaters.

(C) 2017 The Author(s)

Published by S. Karger AG, Basel

\section{Introduction}

Traditionally acceptable methods of anesthesia for vitrectomy surgery include general anesthesia, retrobulbar, peribulbar, or sub-Tenon's anesthesia. Each of these methods has its own potential for complications that can vary from minor to severe. For example, with retrobulbar anesthesia, complications include retrobulbar hemorrhage, perforation of the ocular globe, occlusion of the artery and/or the vein of the retina, retinal detachment [1], subarachnoid injection [2], intracranial diffusion [3], and subsequent decrease in vision, ophthalmoplegia, and even variable degrees of central nervous system symptoms and respiratory depression [2]. Recently, the minimally invasive 27-gauge vitrectomy has become more widely used in vitreoretinal surgeries, with low rates of operative and postoperative complications across varied surgical indications [4-6].

Floaters (muscae volitantes) are perceived by patients as a serious medical condition that has a significant negative impact on their vision and quality of life $[7,8]$. However, it has not been considered as a severe medical problem by most ophthalmic practitioners. Though neodymium-doped yttrium aluminum garnet vitreolysis is also considered [9], small-gauge vitrectomy seems to be the only effective therapy of symptomatic floaters at present [10, 11]. Vitrectomy surgery for vitreous floaters is considered straighter forward than other vitreoretinal surgeries, since no very peripheral vitrectomy is necessary $[10,12,13]$. Here, we report 27-gauge pars plana vitrectomy for symptomatic vitreous floaters with topical anesthesia.

\section{Case Presentation}

The inclusion criteria for vitrectomy for symptomatic floaters were mainly based on the chief complaint of the patient and the observation of the central vitreous opacity crumb. It should be noted that the subjective symptoms lasted longer than 3 months, and disturbed the patients' life moderately or severely.

Case 1

A 32-year-old male presented with a 2-year history of symptomatic floaters in the right eye. He had previously been seen elsewhere for the same problem and had received neodymium-doped yttrium aluminum garnet laser vitreolysis for the right eye. This was done on 3 occasions. He did not improve with this therapy. Best-corrected visual acuity (BCVA) was $20 / 20$ in both eyes upon presentation. 


\section{Case Reports in Ophthalmology}

\begin{tabular}{l|l}
\hline Case Rep Ophthalmol 2017;8:35-39 \\
\hline DOI: $10.1159 / 000453332$ & $\begin{array}{l}\text { ( } 2017 \text { The Author(s). Published by S. Karger AG, Basel } \\
\text { www.karger.com/cop }\end{array}$ \\
\hline
\end{tabular}

Lin et al.: 27-Gauge Vitrectomy for Symptomatic Vitreous Floaters with Topical Anesthesia

\section{Case 2}

A 21-year-old male presented with a 5-year history of symptomatic floaters in the left eye. Upon presentation, BCVA was 20/20 in both eyes. No treatment had previously been performed for the floaters.

\section{Case 3}

A 28-year-old female presented with a 1-year history of symptomatic floaters in the right eye. BCVA was $24 / 20$ in both eyes upon presentation. She had previously been subjected to LASIK surgery for both eyes and vitrectomy for floaters (retrobulbar anesthesia) for the left eye. No treatment for the floaters in the right eye had previously been performed.

Examination showed vitreous opacity in the patients presented. The diagnosis of symptomatic vitreous opacity was made. Details of the preoperative characteristics of these patients are presented in Table 1.

The conditions were explained to the patients, and the option of watchful waiting was offered. Vitrectomy was discussed, including potential risks and benefits. They agreed to proceed with surgery. It was felt that with full pupil dilation and with an indirect wide-angle viewing system, most of the vitreous could be removed without scleral indentation. Therefore, it was felt that topical anesthesia would be safe. 27-gauge sutureless three-port pars plana vitrectomy surgeries with topical anesthesia were performed.

At the beginning of this surgery, topical proparacaine hydrochloric $(0.5 \%$ Alcaine: Alcon, TX, USA) was instilled 3 times in 5-min intervals. Standard three-port cannulae (Constellation; Alcon, Inc., Fort Worth, TX, USA) in the superior-nasal, superior-temporal, and inferiortemporal were established. The central and peripheral vitreous was removed without performing posterior vitreous detachment, and the total duration of the surgery was approximately 8-10 min. All surgical procedures were performed by the same surgeon (R.H.W.). The patients did not experience pain during surgery. No intraoperative anesthesia supplementation or postoperative analgesics were required.

At postoperative day 7, the intraocular pressure and BCVA were almost recovered to that on the preoperative day. All these patients reported that their floaters had disappeared. They enunciated a high level of satisfaction both with the procedure and the outcome. At postoperative month 3, the BCVA were all the same as on the preoperative day. Furthermore, no postoperative complications occurred in these patients (Table 1).

\section{Discussion}

More surgeons are trying to perform minimally invasive vitrectomy (23- or 25-gauge) for various vitreoretinal diseases with topical anesthesia, due to its safety (without complication reported so far) and efficacy (pain tolerance) [14, 15]. The maximal pain occurred during trocar entry and scleral indentation with topical anesthesia [14, 15]. However, the majority of patients (67-100\%) tolerated the procedure without any additional anesthetic agent $[14,15]$. Compared to other vitrectomy surgeries, the surgery procedure for symptomatic vitreous floaters is much simpler, mainly reflecting in the nonuse of scleral indentation, photocoagulation, and the apparently short surgery duration. Although the sclera is 
unavoidably pierced during microcannula establishment, the use of a more minimally invasive 27-gague trocar may reduce the pain.

To our knowledge, this is the first reported case series of 27-gauge vitrectomy for significant vitreous floaters with topical anesthesia. The surgery preparation time could be reduced for at least $5 \mathrm{~min}$ because the retrobulbar or peribulbar anesthesia could be omitted. We believe that this elimination could also reduce the patients' subjective fear and anxiety. In this report, the patients did not experience apparent pain during surgery, not even during the trocar entry. As mentioned above, this may be due to the use of smaller microcannulae. The surgeon did not feel any discomfort due to eyeball movement/squeezing as expected. Furthermore, the surgery was successfully performed without complications, and the visual acuity of the patient remained unchanged postoperatively. In summary, topical anesthesia can be considered as a safe and effective option for 27-gauge vitrectomy in patients with symptomatic vitreous floaters. However, due to important limitations, such as a small sample of the cases, no questionnaire used to assess the sense of pain, and the lack of a control group, further studies are warranted.

\section{Statement of Ethics}

Informed consent was obtained from the patients.

\section{Disclosure Statement}

The authors have no conflicts of interest to disclose.

\section{References}

1 Vestal KP, Meyers SM, Zegarra H: Retinal detachment as a complication of retrobulbar anesthesia. Can J Ophthalmol 1991;26:32-33.

-2 Ahn JC, Stanley JA: Subarachnoid injection as a complication of retrobulbar anesthesia. Am J Ophthalmol 1987;103:225-230.

-3 Marques-Gonzalez A, Onrubia-Fuertes X, Bellver-Romero J, Seller Losada JM, Pertusa-Collado V, Barbera-Alacreu M. Intracranial diffusion. A complication of retrobulbar anesthesia (in Spanish). Rev Esp Anestesiol Reanim 1997;44:284-286.

4 Mitsui K, Kogo J, Takeda H, et al: Comparative study of 27-gauge vs 25-gauge vitrectomy for epiretinal membrane. Eye (Lond) 2016;3D:538-544.

5 Khan MA, Shahlaee A, Toussaint B, et al: Outcomes of 27 gauge microincision vitrectomy surgery for posterior segment disease. Am J Ophthalmol 2016;161:36-43.e1-2.

6 Oshima Y, Wakabayashi T, Sato T, Ohji M, Tano Y: A 27-gauge instrument system for transconjunctival sutureless microincision vitrectomy surgery. Ophthalmology 2010;117:93-102 e102.

7 Zou H, Liu H, Xu X, Zhang X: The impact of persistent visually disabling vitreous floaters on health status utility values. Qual Life Res 2013;22:1507-1514.

8 Webb BF, Webb JR, Schroeder MC, North CS: Prevalence of vitreous floaters in a community sample of smartphone users. Int J Ophthalmol 2013;6:402-405.

9 Delaney YM, Oyinloye A, Benjamin L: Nd:YAG vitreolysis and pars plana vitrectomy: surgical treatment for vitreous floaters. Eye (Lond) 2002;16:21-26. 
Lin et al.: 27-Gauge Vitrectomy for Symptomatic Vitreous Floaters with Topical Anesthesia

10 Sebag J, Yee KM, Wa CA, Huang LC, Sadun AA: Vitrectomy for floaters: prospective efficacy analyses and retrospective safety profile. Retina 2014;34:1062-1068.

11 Sommerville DN: Vitrectomy for vitreous floaters: analysis of the benefits and risks. Curr Opin Ophthalmol 2015;26:173-176.

12 Milston R, Madigan MC, Sebag J: Vitreous floaters: etiology, diagnostics, and management. Surv Ophthalmol 2016;61:211-227.

13 Ivanova T, Jalil A, Antoniou Y, Bishop PN, Vallejo-Garcia JL, Patton N: Vitrectomy for primary symptomatic vitreous opacities: an evidence-based review. Eye (Lond) 2016;30:645-655.

14 Tang S, Lai P, Lai M, Zou Y, Li J, Li S: Topical anesthesia in transconjunctival sutureless 25-gauge vitrectomy for macular-based disorders. Ophthalmologica 2007;221:65-68.

15 Mahajan D, Sain S, Azad S, Arora T, Azad R: Comparison of topical anesthesia and peribulbar anesthesia for 23-gauge vitrectomy without sedation. Retina 2013;33:1400-1406.

Table 1. Preoperative and postoperative characteristics of the patients

\begin{tabular}{llll}
\hline & Case 1 & Case 2 & Case 3 \\
\hline Age, years & 32 & 21 & 28 \\
Gender & male & male & female \\
Spherical equivalent, D & 0.50 & -2.50 & -0.25 \\
Axial length, mm & 24.08 & 24.85 & 26.92 \\
Preoperative BCVA & $20 / 20$ & $20 / 20$ & $24 / 20$ \\
BCVA at month 3 & $20 / 20$ & $20 / 20$ & $24 / 20$ \\
Preoperative IOP & 18 & 16 & 14 \\
IOP at month 3 & 17 & 17 & 16 \\
Pain experience & no & no & no \\
Complication & no & no & no \\
\hline
\end{tabular}

BCVA, best-corrected visual acuity; IOP, intraocular pressure. 